\title{
BRIEF
}

\section{A Prescription for Patient Centered Care Utilizing Structured Narrative Life History Interviews with Pharmacy Learners.}

\author{
Susan Nathan, MD, ${ }^{\text {a,b,c,d }}$ Adam B. Woolley, PharmD, MEd, ${ }^{\text {a,e }}$ Lauren Finlay, PharmD, , ,f Jennifer Moye, PhD ${ }^{\text {b,c }}$ \\ ${ }^{\text {a }}$ VA Boston Healthcare System, Jamaica Plain, Massachusetts \\ ${ }^{\mathrm{b}}$ VA New England Geriatric Research Education and Clinical Center (GRECC) \\ ${ }^{\mathrm{c}}$ Harvard Medical School \\ ${ }^{\mathrm{d}}$ Boston University, School of Medicine, Boston, Massachusetts \\ ${ }^{\mathrm{e}}$ Northeastern University, Bouve College of Health Sciences, Boston, Massachusetts \\ ${ }^{\mathrm{f}}$ Massachusetts College of Pharmacy and Health Sciences, Boston, Massachusetts
}

Corresponding Author: Susan Nathan, VA Boston Healthcare System, 150 S Huntington Avenue, Jamaica Plain, MA 02130. Tel: 857-203-5858. Email: Susan.Nathan@va.gov

Submitted September 9, 2020; accepted April 14, 2021; ePublished April 2021

Objective. We incorporated the My Life, My Story experience into pharmacy learner rotations and assessed the feasibility, impact on self-reported patient-centered care competencies, and learning feedback.

Methods. Fourth year professional pharmacy students (P-4), first year (PGY-1) and second year (PGY-2) pharmacy residents at VA Boston Health care System identified a patient during their rotation with whom to complete an interview and written story following a guide. Learners completed anonymous, voluntary, pre and post-surveys online to assess their self-perceived patient centered care competencies, the impact and overall perceptions of the experience. Additionally, the total number of learners and stories were tracked through medical record extraction.

Results. Over two and a half years 34 pharmacy learners (P-4 (28), PGY-1(4), PGY-2(2)) completed 40 Veteran life stories. Of these, 9 of 34 (26\%) completed the optional, anonymous pre-survey and 16 of 34 (47\%) completed the postsurvey. On a Likert scale $(1=$ poor $-5=$ excellent $)$, learners reported a statistically significant improvement in their ability to let the patient tell their story, view the patient as a whole person, and show care and compassion. Overall, participants reported that the learning experience was a good use of their time to a great (56\%) or large (28\%) extent and helped foster a positive relationship with patients.

Conclusion. Integrating the My Life, My Story experience into pharmacy learning experiences may assist in developing patient centered care skills in the clinical setting.

Keywords: patient centered care; pharmacy education; storytelling

\section{INTRODUCTION}

Pharmacy educators have recognized the need for humanistic approaches in their emphasis on both patientcentered care and affective domain learning. Specifically, in 2016, the Accreditation Council for Pharmacy Education (ACPE) revision of accreditation standards responded to the Institute of Medicine's (IOM) call to provide patient-centered care (PCC), defined as providing care that is respectful of and responsive to individual patient preferences, needs, and values, highlighting PCC in standard 2.1. ${ }^{1,2}$ PCC came to the fore in the health care lexicon with the 2001 IOM report which identified PCC as one of six core features of an effective health care system, to include a respect for patient values, preferences and shared decision making into the provision of health care. ${ }^{3}$ In addition, the revised ACPE accreditation standards call for curricular activities and experiences related to affective domain learning in growing competence both in practice and care and in personal and professional development (Standard 3, 4, 12). Affective domain learning is one of the three learning domains suggested by Bloom's Taxonomy involving emotions, values and attitudes. ${ }^{4,5}$

Various frameworks exist for incorporating humanistic learning into pharmacy curriculum and have been reported in the literature. Incorporating personally-oriented cases versus clinically oriented cases in class led to better outcomes. ${ }^{6}$ Drs. Young and Anderson showed that students performed better when exposed to material formatted with a personal narrative and reported that they were better able to empathize with their patient cases and had an improved understanding of how patient compliance effects clinical outcomes. Courses utilizing case studies, book clubs, and reflective journaling may help develop pharmacy students' emotional intelligence as other approaches to humanistic learning. ${ }^{7,8}$ While the important role played by humanistic learning in pharmacy education has been recognized, many of these experiences are 
offered in the pre-clinical years or later in the curriculum in an elective capacity. An innovative framework for incorporating this type of learning during Advanced Pharmacy Practice Experiences (APPEs) is warranted. The My Life, My Story (MLMS) program is one method to incorporate personally oriented cases.

MLMS was originally developed at the William S. Middleton Memorial Veterans Hospital in Madison, Wisconsin, with staff members performing life story interviews. MLMS connects learners and Veterans to elicit a life story which is integrated into care via the electronic medical record. Veteran reception for this project has been overwhelmingly favorable, and most providers agreed that reading the stories was both a good use of clinical time and would improve treatment of their Veteran participants. ${ }^{9,10}$

MLMS program implementation and its reported impact across learners from multiple profession at our institution has been described elsewhere. ${ }^{11}$ This article provides a descriptive report of the MLMS training experience as it has been built directly into the rotation experience of pharmacy learners to provide humanistic learning during APPE.

\section{METHODS}

Learner-interviewers completed a life story interview using standardized question prompts. Sample questions included, where did you grow up and what was it like; what prompted you to join the military; what are you are proud of in your life; what have you learned along the way that has helped you. The interview was written into a first-person narrative with a target length of roughly 1,000 words. The Veteran was always offered the opportunity to review the story, usually read back by the learner with corrections made in real time. The story was entered into the electronic health record with the Veteran's approval. Detailed instructions including suggested interview questions were provided to the participant. ${ }^{12}$ After completion of the story, interviewers debriefed their experience with the intervention leader or preceptor using a debrief guide provided in the facilitator materials. ${ }^{13}$ Clinical concerns that emerged during the interview, if any, were addressed with the preceptor or relevant clinical team.

There was no funding for this project within this institution. The program team was made up of staff members involved in clinical education or direct learner supervision. As part of program evaluation, learners were asked to complete a voluntary pre and post anonymous online survey. The site director sent out an email containing program instructions and support documents along with the pre and post survey links at the beginning of rotation. The site director reminded the trainees to respond to the pre-survey at the beginning and the post-survey at the end of the rotation. The Research and Development Committee of VA Boston Health care System determined the project to constitute program evaluation and not research.

A pre and post survey was developed to evaluate learner experience. To assess PCC competencies we adapted the Consultation and Relational Empathy (CARE) Measure as we could not find a tool to assess learner perceptions of PCC. ${ }^{14}$ The CARE measure is validated to assess patient perceptions of empathy. In this intervention we selected five PCC items from the CARE measure that we hypothesized may be most influenced by MLMS: be interested in the whole person, show care and compassion, really listen, let the patient tell their story, and make the patient feel at ease (Table 1). Learners were asked to rate their self-perception of their ability in each of five areas on a 5-point Likert scale $(1=$ poor 5 = excellent). On the post- survey, in addition to addressing PCC ratings, participants provided program feedback in four domains: (1) Rating on a 5-point Likert scale as to "this was a good use of my time"; data on program participation including (2) number of stories completed and (3) time spent on each element of the process; (4) open ended responses to (a) what was most valuable; (b) why is it important; (c) what would they change.

Descriptive analyses (percent, mean) describe implementation characteristics, self-perceptions of PCC, and whether MLMS was a good use of time. For the purposes of comparing baseline and post-MLMS ratings of PCC competencies we used one sample t-tests (using the baseline mean as a specified constant) as we were not able to use paired scores due to the anonymous nature of the survey. Analyses were performed in SPSS version 22.

\section{RESULTS}

Between 7/1/2016 and 2/12/2019, 34 pharmacy learners (28 fourth year professional pharmacy students (P-4), four first year pharmacy residents (PGY-1), two second year pharmacy residents (PGY-2)) participated in the MLMS program and completed 40 Veteran life stories. Participants represented approximately $62 \%$ of total pharmacy learners at the medical center over the same time. Of the 34 participants, nine $(26 \%)$ completed the optional, anonymous pre-survey and 16 (10 P-4 students, four PGY-1, and two PGY-2 residents) of 34 (47\%) completed the post survey. Twenty-nine stories were written by P-4 students and 11 stories were written by six residents (four PGY-1 and two PGY-2). The largest self-reported time expenditure of the project was on the interview, which took an average of 56.67 minutes $(S D=27.04)$ followed by the writing $(M=47.33$ minutes, $S D=32.18)$, reading back $(M=18.08$ minutes, $S D=14.95)$ and editing $(M=$ $13.85, S D=17.34)$. An excerpt from one such interview: 'Right now, I can't breathe or walk; I walk with a cane. But I 
have no regrets. I think I did everything I thought I could accomplish. Tell anyone who reads this to enjoy life every single day, because you don't know what's going to come tomorrow. I didn't realize that until I was here. If you live life by this rule, you'll live a good life.'

In comparison of pre and post-survey there was a statistically significant difference in three PCC competencies (Table 1), namely being interested in the patient as a whole person, showing care and compassion, and letting the patient tell their story. Overall, participants reported that the learning experience was a good use of their time to a great (56\%) or large $(28 \%)$ extent and helped foster a positive relationship with patients. Exemplar comments from pharmacy learners included:

I think it allows the patient to express who they are and where they come from. It gives them an identity outside of their health care conditions and helps us as health care providers to understand the patient.";

"Interesting insight into what's really important to a patient, particularly important in a palliative care/hospice setting. Helps better meet their needs, as well as informing the families about the patient's real wishes."; "It is amazing to hear stories and life experiences that are different and also similar to my own, separated by decades. Stories about the Vietnam War are so real, fascinating, and sad. The experiences these Veterans had there are remarkable."

\section{DISCUSSION}

Humanistic activities in pharmacy education are recognized as important to the development of an effective and empathic clinician. At the same time, many of these offerings have a stronger presence in the pre-clinical curriculum. With later offerings presented as optional, students already interested in a humanistic approach to care may self-select in for participation. The elective nature of these experiences also presents a mixed message, placing humanistic educational experiences on the fringe of, rather than central to patient care.

We found it feasible to implement MLMS specifically with advanced undergraduate P-4 students as well as post graduate residents. While the learners in our program were P-4 or post-graduate, this program could be feasible for students earlier in the pharmacy curriculum. This could be introduced as part of the first patient program utilized in first year pharmacy students. Pharmacy learners reported that MLMS enhanced PCC competencies, most notably the ability to see the whole person and was a good use of their time, consistent with reports of learners and staff members from diverse professions. ${ }^{10,11}$

In The Courage To Teach, Parker Palmer wrote "... Everything depends on the lenses through which we view the world. By putting on new lenses, we can see things that would otherwise remain invisible." ${ }^{15}$ The MLMS program is a way for learners to see patients through a new lens that will ultimately help them in their development as clinicians.

There are several limitations to our descriptive report findings. The pre-post assessment was modified midway through the assessment due to variability of students receiving the pre-test routinely before initiation of the rotation. We were not able to match pre and post responses. Further, we did not ask pharmacy participants to identify their training level on the survey and were unable to compare differing level of impact on learners at different states of training. Additionally, these findings are based on student self-report, which may be inflated and do not include summative learning outcomes. ${ }^{16-18}$ Additionally, the sample size and response rate were small. Therefore, there is the potential for non-response bias such that learners who were less favorably inclined towards MLMS did not answer the voluntary survey. Further, we used the CARE measure, which is designed to assess empathy, to assess PCC because we could not find a validated tool to assess learner perceptions of PCC. Future evaluations would be indicated to further assess patient satisfaction with the process or include external evaluation by preceptors on various PCC learning domains. In the setting of the current coronavirus pandemic, with social isolation the norm, medical centers limiting visitors and a significant portion of patient care done virtually, the ability to connect, build therapeutic alliance and be interested in the whole person takes on even heightened relevance than ever before.

\section{CONCLUSION}

Incorporating patient story telling is a novel approach in helping pharmacy learners develop important skills. This method is easily replicable, and schools of pharmacy may consider adding it to current preceptor toolkits in an effort to prepare students for real world practice and the practice of patient centered care. 


\section{ACKNOWLEDGEMENTS}

This material is the result of work supported with resources and the use of facilities at VA Boston Health care System. Contents do not represent the views of VA or the United States Government. We are grateful for the generosity of the Veterans who have shared their stories and the learners who have borne witness to these stories. We thank Kelly Doherty for her assistance in project management, and for the support of the My Life, My Story team and the leadership at VA Boston Health care System.

\section{REFERENCES}

1. Greiner AC, Knegel E, eds. Institute of Medicine Committee on the Health Professions Education Summit, in Health Professions Education: A Bridge to Quality. 2003. Washington, DC: National Academies Press; 2003.

2. Accreditation Council for Pharmacy Education. Accreditation Standards and Key Elements for the Professional Program in Pharmacy Leading to the Doctor of Pharmacy Degree ("Standards 2016"). Published February 2015. https://gcc01.safelinks.protection.outlook.com/?url=https\%3A\%2F\%2Fwww.acpeaccredit.org\%2Fpdf\%2FStandards2016FINAL.pdf\&amp;data=04\%7C01\%7C\%7C0620fdba48fd4deba51708d8eb 060f79\%7Ce95f1b23abaf45ee821db7ab251ab3bf\%7C0\%7C0\%7C637517758548752556\%7CUnknown\%7CTW FpbGZsb3d8eyJWIjoiMC4wLjAwMDAiLCJQIjoiV2luMzIiLCJBTiI6Ik1haWwiLCJXVCI6Mn0\%3D\%7C1000 \&amp;sdata=Rxt41IPJ7JiTVhZx2kyOCspp5uW9fVG6XY\%2BVD3AgfUw\%3D\&amp;reserved=0. Accessed April 9, 2021.

3. Institute of Medicine Committee on Quality of Health Care in America, in Crossing the Quality Chasm: A New Health System for the 21st Century. Washington, DC: National Academies Press; 2001.

4. Krathwohl DR, Bloom BS, Masia BB. Taxonomy of educational objectives, the Classification of Educational Goals. Handbook II: The affective domain, ed. D. McKay. New York, NY; 1964

5. $\quad$ Clark D. Bloom's Taxonomy: Affective Domain. 1999.

https://www.honolulu.hawaii.edu/sites/www.honolulu.hawaii.edu/files/assessment-bloom-taxonomyaffective.pdf. Accessed April 9, 2021.

6. Young LM, Anderson RP. The Use of Personal Narrative in Classroom Case Study Analysis to Improve Longterm Knowledge Retention and Cultivate Professional Qualities in Allied Health Students. J Microbiol Biol Educ. 2010;11(2):107-12.

7. Vogt EM, Finley PR. Heart of Pharmacy: A course exploring the psychosocial issues of patient care. Am J Pharm Educ. 2009;73(8):149.

8. Plake KS. Book club elective to facilitate student learning of the patient experience with chronic disease. Am J Pharm Educ. 2010;74(3):37.

9. $\quad$ Ringler T, et al. Using Life Stories to Connect Veterans and Providers. Fed Pract. 2015;32(6):8-14.

10. Roberts TJ, Ringler T, Krahn D, et al. The My Life, My Story Program: Sustained Impact of Veterans' Personal Narratives on Healthcare Providers 5 Years After Implementation. Health Commun. 2020:1-8.

11. Nathan S, Fiore LL, Saunders S, et al. My life, my story: Teaching patient centered care competencies for older adults through life story work. Gerontol Geriatr Educ. 2019:1-14.

12. Nathan S, Topor D. VA Boston My Life My Story Implementation Guide: Trainee version. https://www.boston.va.gov/Education/Faculty_Development/My-Life_My-Story/Implementation_GuideTrainee version.pdf. Accessed April 9, 2021.

13. Nathan S, Topor D. VA Boston My Life My Story Implementation Guide: Faculty version. https://www.boston.va.gov/Education/Faculty_Development/My-Life_My-Story/VA-Boston_My-Life_MyStory_Implementation_Guide.pdf. Accessed April 9, 2021.

14. Mercer SW, Maxwell M, Heaney D, et al. The consultation and relational empathy (CARE) measure: Development and preliminary validation and reliability of an empathy-based consultation process measure. Fam Pract. 2004;21(6):699-705.

15. Palmer PJ. The Courage to Teach: Exploring the Inner Landscape of a Teacher's Life. San Francisco, CA: JosseyBass; 1998.

16. Valdez CA, Thompson D, Ulrich H, et al., A comparison of pharmacy students' confidence and test performance. Am J Pharm Educ. 2006;70(4):76.

17. Morgan PJ, Cleave-Hogg D. Comparison between medical students' experience, confidence and competence. Med Educ. 2002;36(6):534-9.

18. Barnsley L, Lyon PM, Ralston SJ, et al. Clinical skills in junior medical officers: A comparison of self-reported confidence and observed competence. Med Educ. 2004;38(4):358-67. 
Table 1. Differences in Patient Centered Care Competencies from Baseline to Post Survey

\begin{tabular}{|c|c|c|c|c|c|}
\hline Item & Definition & Surve & Mean $(S D)$ & $t$ & $p$ value \\
\hline \multirow{4}{*}{$\begin{array}{l}\text { Be interested in } \\
\text { the patient as a } \\
\text { whole person } \\
\text { Show care and } \\
\text { compassion }\end{array}$} & \multirow{2}{*}{$\begin{array}{l}\text { Asking/ knowing relevant details about the } \\
\text { patient's life and situation; not treating the } \\
\text { patient as "just a number" }\end{array}$} & Pre & $4.40(.97)$ & \multirow[t]{2}{*}{4.09} & \multirow[t]{2}{*}{$<.01$} \\
\hline & & Post & $4.81(.40)$ & & \\
\hline & \multirow{2}{*}{$\begin{array}{l}\text { Seeing genuinely concerned, connecting } \\
\text { with the patient on a human level; not being } \\
\text { indifferent or detached }\end{array}$} & Pre & $4.50(.85)$ & \multirow[t]{2}{*}{2.25} & \multirow[t]{2}{*}{$<.05$} \\
\hline & & Post & $4.75(.45)$ & & \\
\hline \multirow[t]{2}{*}{ Really listen } & \multirow{2}{*}{$\begin{array}{l}\text { Pay close attention to what the patient is } \\
\text { saying, not looking at notes or computer as } \\
\text { patient is talking }\end{array}$} & Pre & $4.30(1.06)$ & \multirow[t]{2}{*}{2.10} & \multirow[t]{2}{*}{.053} \\
\hline & & Post & $4.44(1.13)$ & & \\
\hline \multirow{2}{*}{$\begin{array}{l}\text { Let the patient } \\
\text { tell their story }\end{array}$} & \multirow{2}{*}{$\begin{array}{l}\text { Giving time to fully describe their condition } \\
\text { in their own words; not interrupting, rushing } \\
\text { or diverting }\end{array}$} & Pre & $4.30(1.06)$ & \multirow[t]{2}{*}{3.12} & \multirow[t]{2}{*}{$<.01$} \\
\hline & & Post & $4.75(.58)$ & & \\
\hline \multirow[t]{2}{*}{$\begin{array}{l}\text { Make the patient } \\
\text { feel at ease }\end{array}$} & $\begin{array}{l}\text { Introducing yourself, explaining your } \\
\text { position, being friendly and warm towards } \\
\text { patients, treating patients with respect; not }\end{array}$ & Pre & $4.40(.97)$ & \multirow[t]{2}{*}{0.55} & \multirow[t]{2}{*}{0.59} \\
\hline & cold or abrupt & Post & $4.50(.73)$ & & \\
\hline
\end{tabular}

Note: Baseline survey $n=9$, post survey $n=16$. Items rated on Likert scale $1-5$. 